\title{
Effects of warmed carrier fluid on nefopam injection-induced pain
}

Department of Anesthesiology and Pain Medicine, Myongi Hospital, Goyang, Korea

Hyung Rae Cho, Seon Hwan Kim, Jin A Kim, Jin Hye Min, and Yong Kyung Lee

Background: Nefopam is a non-opioid, non-steroidal analgesic drug with fewer adverse effects than narcotic analgesics and nonsteroidal anti-inflammatory drugs, and is widely used for postoperative pain control. Because nefopam sometimes causes side effects such as nausea, vomiting, somnolence, hyperhidrosis and injection-related pain, manufacturers are advised to infuse it slowly, over a duration of 15 minutes. Nevertheless, pain at the injection site is very common. Therefore, we investigated the effect of warmed carrier fluid on nefopam injection-induced pain.

Methods: A total of 48 patients were randomly selected and allocated to either a control or a warming group. Warming was performed by diluting $40 \mathrm{mg}$ of nefopam in $100 \mathrm{ml}$ of normal saline heated to $31-32^{\circ} \mathrm{C}$ using two fluid warmers. The control group was administered $40 \mathrm{mg}$ of nefopam dissolved in $100 \mathrm{ml}$ of normal saline stored at room temperature $\left(21-22^{\circ} \mathrm{C}\right)$ through the fluid warmers, but the fluid warmers were not activated.

Results: The pain intensity was lower in the warming group than in the control group $(P<0.001)$. The pain severity and tolerance measurements also showed statistically significant differences between groups $(P<$ 0.001). In the analysis of vital signs before and after the injection, the mean blood pressure after the injection differed significantly between the groups $(P=0.005)$, but the heart rate did not. The incidence of hypertension also showed a significant difference between groups $(P=0.017)$.

Conclusions: Use of warmed carrier fluid for nefopam injection decreased injection-induced pain compared to mildly cool carrier fluid. (Korean J Pain 2018; 31: 102-8)

Key Words: Cold temperature; Heating; Nefopam; Pain; Vasoconstriction; Vasodilation.

\section{INTRODUCTION}

Nefopam is a non-opioid, non-steroidal analgesic drug with fewer adverse side effects as compared to those of narcotic analgesics and NSAIDs, and is widely used for postoperative pain control [1].

Because nefopam sometimes causes side effects such as nausea, vomiting, somnolence, hyperhidrosis, headache, blurred vision, and injection pain, manufacturers are advised to infuse it slowly, over 15 minutes. Nevertheless,

Received December 1, 2017. Revised February 26, 2018. Accepted February 27, 2018.

Correspondence to: Yong Kyung Lee

Department of Anesthesiology and Pain Medicine, Myongji Hospital, 55 Hwasu-ro 14beon-gil, Deokyang-gu, Goyang 10475, Korea Tel: +82-31-810-6200, Fax: +82-31-810-6209, E-mail: 05142@mjh.or.kr

(c) This is an open-access article distributed under the terms of the Creative Commons Attribution Non-Commercial License (http:// creativecommons.org/licenses/by-nc/4.0/), which permits unrestricted non-commercial use, distribution, and reproduction in any medium, provided the original work is properly cited.

Copyright (C) The Korean Pain Society, 2018 
pain at the injection site is very common. Furthermore, the slow infusion of nefopam can hinder the rapid resolution of acute pain.

In an attempt to address these problems, we investigated the effect of warmed carrier fluid on nefopam injection pain.

\section{MATERIALS AND METHODS}

This prospective, randomized, single-blind, placebo-controlled study was approved by the Institutional Review Board of our hospital, and was performed after obtaining consent from all participating patients. The study included 20- to 70-year-old patients with American Society of Anesthesiologists physical status I and II, who underwent elective surgery under general anesthesia between January 2017 and February 2017. Only the cases where the catheter was more than $3 \mathrm{~cm}$ away from the elbow crease and proximal crease of the wrist in the anterior aspect of the forearm were included in the study (Fig. 1).

The exclusion criteria were as follows: American Society of Anesthesiologists class III or above; administration of other analgesic or vasoactive drugs; a history

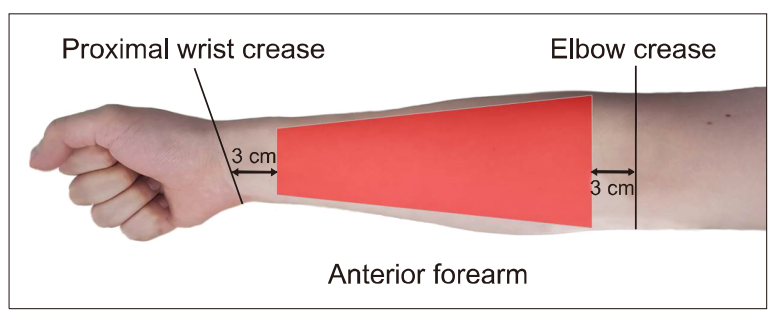

Fig. 1. Insertion site of the catheter based on the inclusion criteria.
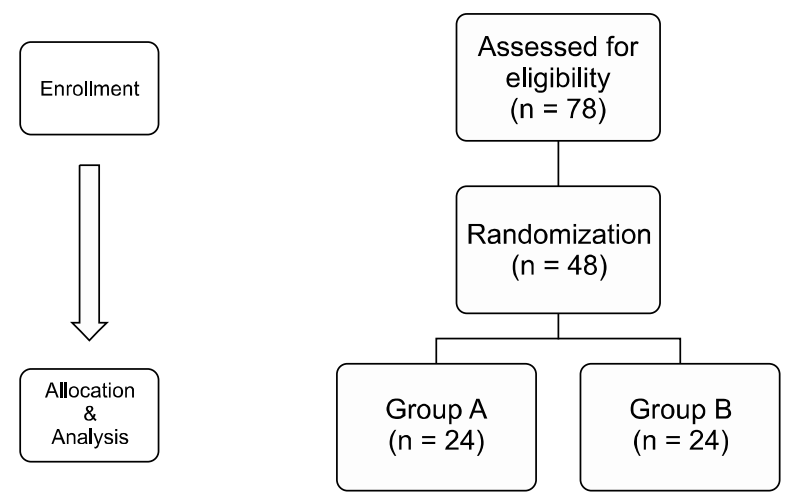

Fig. 2. Flowchart of patient recruitment, randomization and allocation. of cardiovascular, liver or kidney disease; basal heart rate $>100$ beats/min; pain, redness or warm sensation in the intravenous catheterization site. In addition, cases in which the catheter was not cannulated in the anterior aspect of the forearm, was not an 18-gauge catheter, or was within $3 \mathrm{~cm}$ of the elbow crease or the proximal crease of the wrist were also excluded.

A total of 78 patients participated in this study (Fig. 2). Using a computer-generated random number table, 48 patients were selected for testing, of which 24 were assigned to each group, also using a computer-generated random number table (www.randomization.com). There were no statistically significant differences in demographic characteristics between the control and warming groups (Table 1).

The control group was administered nefopam $40 \mathrm{mg}$ dissolved in $100 \mathrm{ml}$ of normal saline stored at room temperature $\left(21-22^{\circ} \mathrm{C}\right)$ through the fluid warmers, but the fluid warming was not activated. In the warming group, the same procedure was carried out, but with the fluid warmer devices activated. Warming was performed at $32-33^{\circ} \mathrm{C}$ with two fluid warmers (Ranger ${ }^{\mathrm{TM}}$ Model 245 Blood/Fluid Warming Unit, Augustine Medical Inc., Eden Prairie, Minnesota, USA, and ANIMEC AM-2S-5A, ELLTEC, Nagoya, Aichi-ken, Japan) (Fig. 3). The power indicators of the fluid warmers were covered with black tape to prevent the patient or experimenter from knowing their operational status, so that the patients would not know which group they belonged to. In the warming group, all devices were preheated for 10 minutes before use to achieve optimum performance. In both groups, the infusion set was equally

Table 1. Demographic Data

\begin{tabular}{lcc}
\hline \multirow{2}{*}{ Parameters } & \multicolumn{2}{c}{ Group } \\
\cline { 2 - 3 } & Control $(n=24)$ & Warming $(n=24)$ \\
\hline Age $(\mathrm{y})$ & $48.4 \pm 12.9$ & $44.6 \pm 15.3$ \\
Sex $(\mathrm{M} / \mathrm{F})$ & $12 / 12$ & $14 / 10$ \\
ASA classification $(\mathrm{I} / \mathrm{II})$ & $14 / 10$ & $11 / 13$ \\
Weight $(\mathrm{kg})$ & $65.7 \pm 10.6$ & $70.8 \pm 19.5$ \\
Height $(\mathrm{m})$ & $1.6 \pm 0.1$ & $1.7 \pm 0.1$ \\
BMI $\left(\mathrm{kg} / \mathrm{m}^{2}\right)$ & $24.3 \pm 3.4$ & $24.6 \pm 5.0$ \\
Vein diameter $(\mathrm{mm})$ & $3.1 \pm 1.0$ & $2.9 \pm 0.9$ \\
\hline
\end{tabular}

Data are presented as means $\pm S D$ values or the number of patients. There were no significant differences between the two groups. ASA: american society of anesthesiology, BMI: body mass index. 


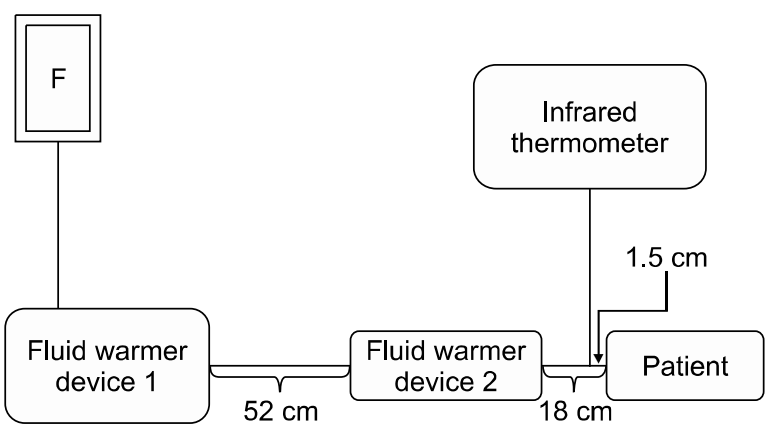

Fig. 3. Fluid warming devices used in this study. Fluid warmer device 1: Ranger ${ }^{\mathrm{TM}}$ Model 245 Blood/Fluid Warming Unit, Augustine Medical Inc., USA. Fluid warmer device 2: ANIMEC AM-2S-5A, ELLTEC, Japan.

primed with experimental fluid, which was administered dropwise at a rate of $270 \mathrm{ml} / \mathrm{h}$. Each experimental drug was administered as a premedication in the post-anesthetic care unit prior to transfer to the operating room.

Before starting nefopam infusion, mean blood pressure (MBP) and heart rate (HR) were checked; the drug was then administered. Each patient was asked to use a numerical rating scale (NRS; $0=$ no pain, 10 = worst pain imaginable) to rate the maximum pain experienced during the 5-minute period following initiation of the injection. Pain severity was categorized and recorded according to the NRS score $(0=$ none, $1-3=$ mild, $4-6=$ moderate, $7-10=$ severe). If the patient complained of pain at the injection site or asked to stop infusion, this was recorded as unendurable pain.

We noted any occurrence of redness, swelling, and tenderness at the intravenous injection site. Vein diameter was measured using ultrasonography by an anesthesiologist who was unaware of the study (Fig. 4). Also, side effects such as hypertension (systolic blood pressure $>140$ $\mathrm{mmHg}$ or diastolic blood pressure $<50 \mathrm{mmHg}$ ), tachycardia (HR > 100 beats/min), palpitation, nausea, vomiting, sweating, dizziness, and headache were noted. If the patient complained of severe pain during the $5 \mathrm{~min}$ injection, the injection rate was halved so that the pain disappeared. Pain scores, side effects, and complications were recorded by an anesthesiologist who was not informed about the purpose of the study.

The primary endpoint was the post-injection NRS score, and the secondary endpoints were the pain severity, tolerance, and side effects. In a pilot study conducted to assist in setting the sample size, the average post-in-

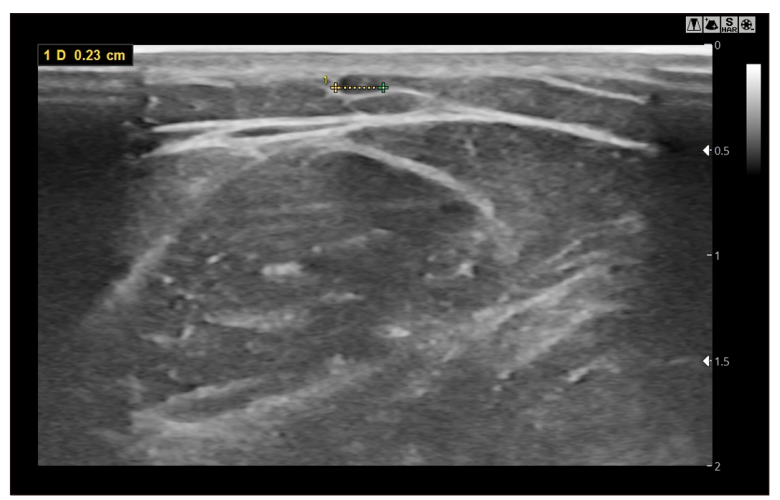

Fig. 4. Measurement of vein diameter using ultrasonography.

jection NRS scores of the control and warming groups were $3.97 \pm 1.93$ and $2.10 \pm 1.28$, respectively. Assuming $\alpha=$ 0.05 and power $=0.95,21$ patients were expected to be needed per group. The dropout rate was anticipated to be $10 \%$, therefore the study was planned with a total of 48 patients, 24 from each group. Statistical analysis was done using SPSS v16.0 (SPSS Inc., Chicago, Illinois). The t-test or the Mann-Whitney $U$ test were used for analyses of the NRS scores and changes in vital signs. A likelihood ratio test for trend was used for analysis of pain severity, and the Chi-square test or Fisher's exact test (if cell size $\leq$ $5)$ were used for analysis of pain tolerance and side effects. $P$ values less than 0.05 were considered statistically significant.

\section{RESULTS}

The pain intensity was lower in the warming group than in the control group $(1.88 \pm 1.30$ vs. $4.21 \pm 1.96, P<$ 0.001). The pain severity and tolerance measurements also showed statistically significant differences $(P<0.001)$.

In the analysis of vital signs before and after the injection, the MBP after injection was significantly different between the groups $(P=0.005)$, but the HR was not (Table 2).

The incidence of hypertension also showed a significant difference between groups $(P=0.017$, Table 3$)$.

\section{DISCUSSION}

This study showed that mildly warmed carrier fluid (31$32^{\circ} \mathrm{C}$ ) significantly reduced pain during injection of 
Table 2. Comparisons between Control and Warming Groups, of Pain and Vital Signs after Nefopam Injection

\begin{tabular}{|c|c|c|c|c|c|}
\hline & Control group $(n=24)$ & Warming group $(n=24)$ & OR or MD & $95 \% \mathrm{Cl}$ & $P$ value \\
\hline Pain intensity (NRS) & $4.21 \pm 1.96$ & $1.88 \pm 1.30$ & 2.33 & $1.37-3.30$ & $<0.001$ \\
\hline Pain severity & & & & & $<0.001$ \\
\hline None & 0 & 5 & & & \\
\hline Mild & 10 & 18 & & & \\
\hline Moderate & 10 & 1 & & & \\
\hline Severe & 4 & 0 & & & \\
\hline Pain tolerance & & & & & $<0.001$ \\
\hline Endurable & 11 & 24 & & & \\
\hline Unendurable & 13 & 0 & & & \\
\hline \multicolumn{6}{|l|}{ MBP } \\
\hline Before injection & $88.36 \pm 10.16$ & $88.53 \pm 10.97$ & -0.17 & $-6.31-5.98$ & 0.957 \\
\hline After injection & $110.46 \pm 11.84$ & $100.64 \pm 11.39$ & 9.82 & $3.07-16.57$ & 0.005 \\
\hline \multicolumn{6}{|l|}{$\mathrm{HR}$} \\
\hline Before injection & $73.04 \pm 10.41$ & $71.62 \pm 8.29$ & 1.42 & $-4.051-6.88$ & 0.604 \\
\hline After injection & $81.38 \pm 13.70$ & $84.79 \pm 9.10$ & -3.42 & $-10.20-3.37$ & 0.315 \\
\hline
\end{tabular}

Data are presented as means \pm SD values or the number of patients (\%). NRS: numerical rating scale, OR: odds ratio, MD: median difference, MPB: mean blood pressure, HR: heart rate. A $P$ value $<0.05$ was considered statistically significant.

Table 3. Incidence of Side Effects and Complications at the Intravenous Injection Site

\begin{tabular}{lcc}
\hline & $\begin{array}{c}\text { Control group } \\
(n=24)\end{array}$ & $\begin{array}{c}\text { Warming group } \\
(n=24)\end{array}$ \\
\hline $\begin{array}{c}\text { Side effects } \\
\text { Hypertension* }\end{array}$ & $19(79.2)$ & $10(41.7)$ \\
Tachycardia & $1(4.2)$ & $1(4.2)$ \\
Nausea & $3(12.5)$ & $3(12.5)$ \\
Vomiting & $1(4.2)$ & $1(4.2)$ \\
Palpitation & $1(4.2)$ & $1(4.2)$ \\
Sweating & $2(8.3)$ & $1(4.2)$ \\
Dizziness & $1(4.2)$ & $1(4.2)$ \\
Headache & $1(4.2)$ & 0 \\
Complications at injection & site & \\
Redness & 0 & 0 \\
Swelling & 0 & 0 \\
Tenderness & 0 & 0 \\
\hline
\end{tabular}

Data are presented as the number of patients (\%). ${ }^{\star} P<0.05$.

nefopam. Compared to Kim et al.'s study [2], the use of warmed carrier fluid in this study allowed the same nefopam dose to be administered over less time (for $30 \mathrm{mg}$, $15 \mathrm{~min}$ vs. $20 \mathrm{~min}$ ), and resulted in a faster infusion rate of nefopam, leading to minimal pain.

Nefopam has been widely used for the treatment and prevention of postoperative pain, because it has no effect on platelet function and no respiratory depression effect [3-5]. The mechanism of action of nefopam has not been fully explained; however, its central analgesic effect might be mediated by inhibiting the reuptake of serotonin, dopamine, and norepinephrine [6,7]. Since nefopam has several side effects, manufacturers are advised to infuse it slowly over 15 minutes to prevent side effects [8]. However, even this slow infusion rate causes side effects such as injection site pain, and furthermore makes it difficult to control acute pain, making clinicians reluctant to use the drug.

There have been many studies aimed at reducing the pain caused by injection of drugs such as propofol and rocuronium [9-11]. Nefopam also causes injection pain, but research on it has not been sufficient. To date, only one study has been conducted to find the most rapid infusion rate of nefopam that does not cause injection pain and severe side effects. Kim et al. [2] compared infusion rates of $60 \mathrm{ml} / \mathrm{h}, 120 \mathrm{ml} / \mathrm{h}$ and $180 \mathrm{ml} / \mathrm{h}$, and reported that the injection pain was lowest at $60 \mathrm{ml} / \mathrm{h}$. They used $30 \mathrm{mg}$ of nefopam diluted in $20 \mathrm{ml}$ of normal saline $(1.5 \mathrm{mg} / \mathrm{ml})$, but the infusion rate was $60 \mathrm{ml} / \mathrm{h}$, which required $20 \mathrm{mi}-$ nutes for complete infusion. The calculated rate $(90 \mathrm{mg} / \mathrm{h})$ was insufficient to control acute pain and was lower than that used in this study $(108 \mathrm{mg} / \mathrm{h})$. We referred to previous studies of the relationship between temperature and pain during injection [12-14], in hopes of finding a way to infuse quickly with minimal pain.

All previous studies had used a temperature of about 
$40^{\circ} \mathrm{C}$, so we also designed the study to use a warming fluid of $40^{\circ} \mathrm{C}$. First, however, we needed to consider two factors related to patient safety: skin burns, and deterioration of the drug, caused by factors such as formation of precipitates or reduction of efficacy. Fortunately, previous studies have shown that a temperature of $40-43^{\circ} \mathrm{C}$ does not cause skin burns or hyperthermia. In order to confirm the drug stability, we conducted the experiments and the experiments confirmed that the potency was not affected, and that denaturing did not occur at a temperature of $41^{\circ} \mathrm{C}$.

In the pilot study, we observed that the temperature of the fluid, injected at a rate of $270 \mathrm{ml} / \mathrm{h}$ in a $21^{\circ} \mathrm{C}$ operating room environment, dropped sharply as it passed through a relatively short $70 \mathrm{~cm}$ IV line (from $41^{\circ} \mathrm{C}$ to $28^{\circ} \mathrm{C}$ ). We found that carrier fluid at a temperature $<28^{\circ} \mathrm{C}$ did not significantly reduce nefopam injection-induced pain (data not shown). The limitations of this Ranger ${ }^{\mathrm{TM}}$ fluid warmer have already been demonstrated in a previous study [15]. To solve this problem, an additional fluid warmer (ANIMEC) was installed in the IV line closer to the catheterized vein. We also needed to consider which type of external measurement would best reflect the actual temperature of the infused fluid. After several attempts, we found that the temperature of the IV line measured with an infrared thermometer $1.5 \mathrm{~cm}$ distal to the catheter best reflected the temperature at which it was actually injected

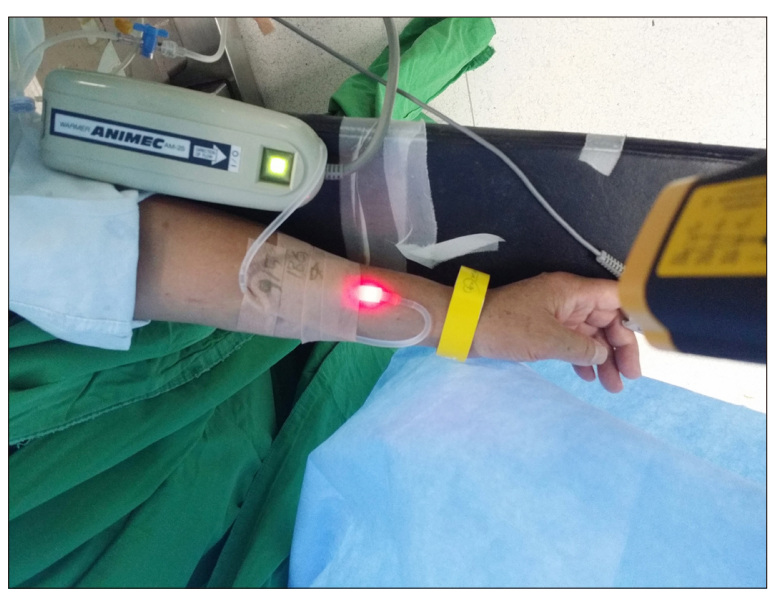

Fig. 5. Illustration of a fluid warmer and measurement of infusion fluid temperature using an infrared thermometer. This picture is from a pilot study. In the study itself, the power indicator of the ANIMEC warmer was covered with black tape.
(Fig. 5). Although no data were formally collected, the difference between the actual temperature of the infused fluid and the measured external temperature was observed to be $<1^{\circ} \mathrm{C}$.

For propofol and rocuronium, it is known that injection pain is caused by inflammatory mediators such as histamine and kinin, or by activation of $\mathrm{C}$-nociceptive fibers due to non-physiological osmotic pressure or $\mathrm{pH}[12,16]$. However, nefopam is almost isotonic, and has a $\mathrm{pH}$ of more than 5 , which makes it difficult to attribute the pain it causes to non-physiological osmotic pressure or $\mathrm{pH}$ [2]. This suggests that consideration should be given to the receptor affinities of nefopam. A recent study showed that nefopam has a strong affinity for the 5-HT2A receptor [17]. Nefopam binds to the 5-HT2A receptors of platelets, and activates them without causing aggregation $[3,18]$. Activated platelets induce secretion of interleukin-1 (IL-1) and IL-8 in vascular endothelial cells, and at the same time bind to leukocytes that secrete IL-6 and tumor necrosis factor-alpha $[19,20]$. Because these two pathways promote localized inflammation, it can be inferred that this is a mechanism by which nefopam induces vascular pain (Fig. 6). In our knowledge, this hypothesis is the first attempt to explain the mechanism of nefopam-induced pain.

Previous studies have suggested that injection pain is reduced by thermal vasodilation [12-14]. While several studies reported vasodilatory effects after heating for more than 20 minutes [21-23], it is doubtful whether heating for less than 5 minutes caused vasodilatory effects in previous studies, or in this study. On the other hand, we know that mildly cool fluid $\left(<22^{\circ} \mathrm{C}\right)$ induces sustained

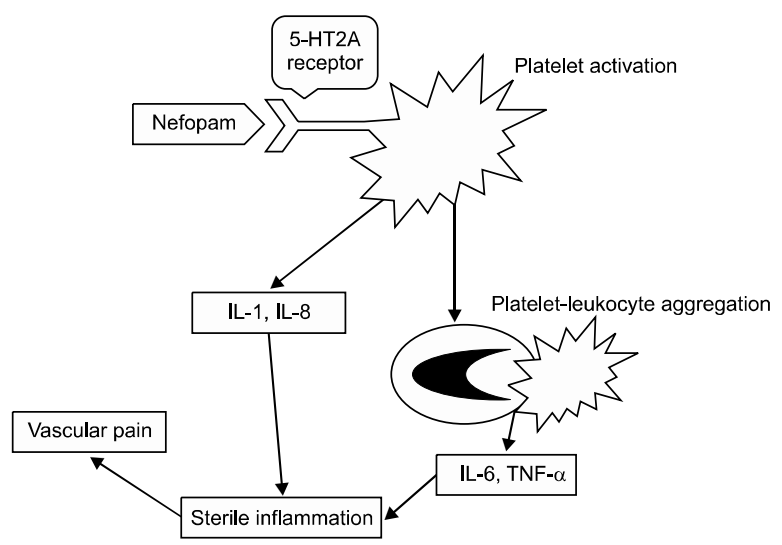

Fig. 6. Diagram illustrating hypothesis concerning linkage between platelet activation and vascular pain. 
vasoconstriction, while a thermoneutral temperature (24$32^{\circ} \mathrm{C}$ ) is expected to alleviate vasoconstriction [24,25]. It is presumed that the relative coolness of the fluid enhanced vasoconstriction, allowing activated platelets and platelet-leukocyte complexes to make better contact with the endothelium, thereby resulting in more severe pain than that in the warming group.

In a quantitative systematic review, the use of nefopam increased the risks of tachycardia and sweating: the incidences were $21.3 \%$ and $8.8 \%$, respectively [5]. In this study, the incidence of tachycardia was about $4 \%$, suggesting that either the concentration or infusion rate of nefopam were different. Patients in both groups from this study showed a high incidence of hypertension ( $>40 \%$ ), probably due to a slight inotropic effect of nefopam [26]. MBP was significantly higher in the control group after nefopam injection than in the warming group; it is presumed that the sympathetic nervous system was further stimulated by the greater pain intensity [27]. Therefore, the use of nefopam in patients requiring precise blood pressure control deserves caution.

Previous studies have suggested ways to reduce injection pain, but they had limitations. First, the diameter of vessels and the catheter insertion site were not controlled. These two factors need to be controlled because they affect the pain experienced during injection. Second, the actual injection temperature was not measured, or the measurement site was not specified in detail. Because we eliminated variability by controlling these factors, we can assert that this study had significantly advantages over previous studies. However, our research design also had drawbacks: it did not evaluate the changes in vessel diameter caused by heating or cooling. Future research will be needed to directly measure and verify the vasomotor effects produced by temperature. In addition, it is difficult to use several heating devices simultaneously in clinical practice. Since the beneficial effect of warmed carrier fluid has been demonstrated in this study, development of an efficient IV-line heating device would help reduce injection-related pain.

In conclusion, use of warmed carrier fluid for nefopam injection decreased injection-induced pain compared to mildly cool carrier fluid.

\section{REFERENCES}

1. Girard $P$, Chauvin M, Verleye M. Nefopam analgesia and its role in multimodal analgesia: a review of preclinical and clinical studies. Clin Exp Pharmacol Physiol 2016; 43: 3-12.

2. Kim YM, Lim BG, Kim H, Kong MH, Lee MK, Lee IO. Slow injection of nefopam reduces pain intensity associated with intravenous injection: a prospective randomized trial. J Anesth 2014; 28: 399-406.

3. Dordoni PL, Della Ventura M, Stefanelli A, lannace E, Paparella P. Rocca B, et al. Effect of ketorolac, ketoprofen and nefopam on platelet function. Anaesthesia 1994; 49: 1046-9.

4. Bhatt AM, Pleuvry BJ, Maddison SE. Respiratory and metabolic effects of oral nefopam in human volunteers. $\mathrm{Br} \mathrm{J}$ Clin Pharmacol 1981; 11: 209-11.

5. Evans MS, Lysakowski C, Tramèr MR. Nefopam for the prevention of postoperative pain: quantitative systematic review. Br J Anaesth 2008; 101: 610-7.

6. Piercey MF, Schroeder LA. Spinal and supraspinal sites for morphine and nefopam analgesia in the mouse. Eur $J$ Pharmacol 1981; 74: 135-40.

7. Heel RC, Brogden RN, Pakes GE, Speight TM, Avery GS. Nefopam: a review of its pharmacological properties and therapeutic efficacy. Drugs 1980; 19: 249-67.

8. Durrieu G, Olivier P, Bagheri H, Montastruc JL. Overview of adverse reactions to nefopam: an analysis of the French Pharmacovigilance database. Fundam Clin Pharmacol 2007; 21: 555-8.

9. Jung KT, Kim HJ, Bae HS, Lee HY, Kim SH, So KY, et al. Effects of lidocaine, ketamine, and remifentanil on withdrawal response of rocuronium. Korean J Anesthesiol 2014; 67: 175-80.

10. Polat R, Aktay M, Ozlü O. The effects of remifentanil, lidocaine, metoclopramide, or ketamine pretreatment on propofol injection pain. Middle East J Anaesthesiol 2012; 21: $673-7$

11. Alipour M, Tabari M, Alipour M. Paracetamol, ondansetron, granisetron, magnesium sulfate and lidocaine and reduced propofol injection pain. Iran Red Crescent Med J 2014; 16 : e16086.

12. Mahajan C, Rath GP, Bithal PK, Prabhakar H, Yadav R, Dube SK. Local warming at injection site helps alleviate pain after rocuronium administration. J Anesth 2010; 24: 845-8.

13. Jeong $\mathrm{M}$, Yoon $\mathrm{H}$. Comparison of the effects of lidocaine pre-administration and local warming of the intravenous access site on propofol injection pain: randomized, doubleblind controlled trial. Int J Nurs Stud 2016; 61: 209-18.

14. Youn AM, Hsu TM. Heated carrier fluids in decreasing propofol injection pain: a randomized, controlled trial. Korean J Anesthesiol 2017; 70: 33-8.

15. Kim DJ, Kim SH, So KY, An TH. Mega Acer Kit ${ }^{\circledR}$ is more 
effective for warming the intravenous fluid than Ranger $^{\mathrm{TM}}$ and ThermoSens $^{\circledR}$ at $440 \mathrm{ml} / \mathrm{h}$ of infusion rate: an experimental performance study. Korean J Anesthesiol 2017; 70: 456-61.

16. Klement W, Arndt JO. Pain on i.v. injection of some anaesthetic agents is evoked by the unphysiological osmolality or $\mathrm{pH}$ of their formulations. $\mathrm{Br} J$ Anaesth 1991; 66: 189-95.

17. Gregori-Puigjané E, Setola V, Hert J, Crews BA, Irwin JJ, Lounkine $\mathrm{E}$, et al. Identifying mechanism-of-action targets for drugs and probes. Proc Natl Acad Sci U S A 2012; 109: 11178-83.

18. Raote I, Bhattacharya A, Panicker MM. Serotonin 2A (5-HT2A) receptor function: ligand-dependent mechanisms and pathways. In: Serotonin receptors in neurobiology. Edited by Chattopadhyay A. Boca Raton (FL), CRC Press. 2007, pp 105-32.

19. Kaplanski G, Porat R, Aiura K, Erban JK, Gelfand JA, Dinarello CA. Activated platelets induce endothelial secretion of interleukin-8 in vitro via an interleukin-1-mediated event. Blood 1993; 81: 2492-5.

20. Neumann FJ, Marx N, Gawaz M, Brand K, Ott I, Rokitta C, et al. Induction of cytokine expression in leukocytes by binding of thrombin-stimulated platelets. Circulation 1997; 95: 2387-94.
21. Christen S, Delachaux A, Dischl B, Golay S, Liaudet L, Feihl $F$, et al. Dose-dependent vasodilatory effects of acetylcholine and local warming on skin microcirculation. J Cardiovasc Pharmacol 2004; 44: 659-64.

22. Minson CT, Berry LT, Joyner MJ. Nitric oxide and neurally mediated regulation of skin blood flow during local heating. J Appl Physiol (1985) 2001; 91: 1619-26.

23. Taylor WF, Johnson JM, O'Leary D, Park MK. Effect of high local temperature on reflex cutaneous vasodilation. J Appl Physiol Respir Environ Exerc Physiol 1984; 57: 191-6.

24. Elstad M, Vanggaard L, Lossius AH, Walløe L, Bergersen TK. Responses in acral and non-acral skin vasomotion and temperature during lowering of ambient temperature. J Therm Biol 2014; 45: 168-74.

25. Bergersen TK, Skytioti M, Elstad M. Cold-induced sympathetic tone modifies the impact of endothelium-dependent vasodilation in the finger pulp. Auton Neurosci 2017; 203: 97-102.

26. Hagemann K, Platte G, Meyer J, Effert S. Haemodynamic effects of nefopam (author's transl). Dtsch Med Wochenschr 1978; 103: 1040-3.

27. Saccò M, Meschi M, Regolisti G, Detrenis S, Bianchi L, Bertorelli $\mathrm{M}$, et al. The relationship between blood pressure and pain. J Clin Hypertens (Greenwich) 2013; 15: 600-5. 